\section{No evidence for heterogeneity in oculopharyngeal muscular dystrophy}

Oculopharyngeal muscular dystrophy (OPMD) is a rare, late onset, autosomal dominant myopathy with dysphagia, bilateral ptosis, and a slowly progressive weakness of facial and limb girdle muscles. Characteristic intranuclear filaments of $10 \mathrm{~nm}$ in diameter can be found in muscle biopsies by electron microscopy. We describe multipoint linkage analysis in two large German families with OPMD confirming the gene locus on chromosome 14q11.2-q13. Neither family has any French ancestors and they are not related, as shown by the different risk haplotypes.

Oculopharyngeal muscular dystrophy (OPMD) is clinically characterised by the following features: bilateral ptosis of the eyelids, dysphagia, and weakness and wasting of other extraocular, facial, and limb girdle muscles with slow progression. The age of onset is usually after 45 years. ${ }^{1}$ Inheritance is clearly autosomal dominant with complete penetrance late in life. Intranuclear filaments are seen in a small percentage of skeletal muscle nuclei by electron microscopy. These filaments are considered specific for OPMD. ${ }^{2}$ Their relationship to the pathogenetic mechanism and their mode of formation are unknown.
In the absence of a family history, two differential diagnoses should be considered: myasthenia gravis and a mitochondrial myopathy (for example, Kearns-Sayre syndrome). Although abnormal mitochondria have been described in muscle biopsies of OPMD patients, ${ }^{3}$ neither a biochemical defect of the respiratory chain nor mutations in the mtDNA have been found. ${ }^{4}$

The majority of cases and families have been reported in French Canadians, where they could be traced back to common French ancestors. ${ }^{5}$ Independent cases have been described in more than 20 countries, ${ }^{6}$ including Germany. ${ }^{78}$ Recently the gene locus for OPMD has been localised to chromosome $14 \mathrm{q} 11.2-\mathrm{q} 13$ in the region of the cardiac alpha and beta myosin heavy chain genes

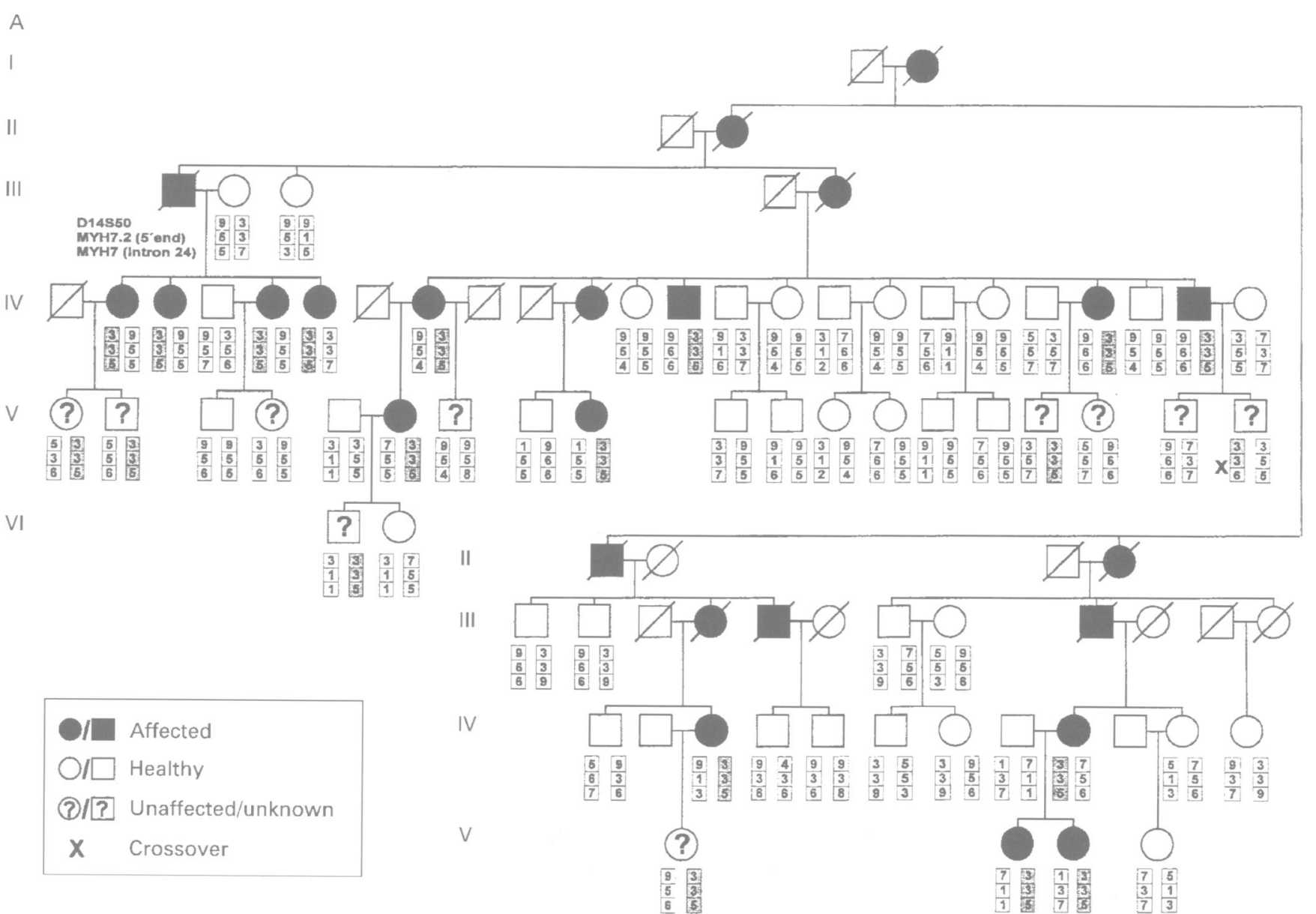

B

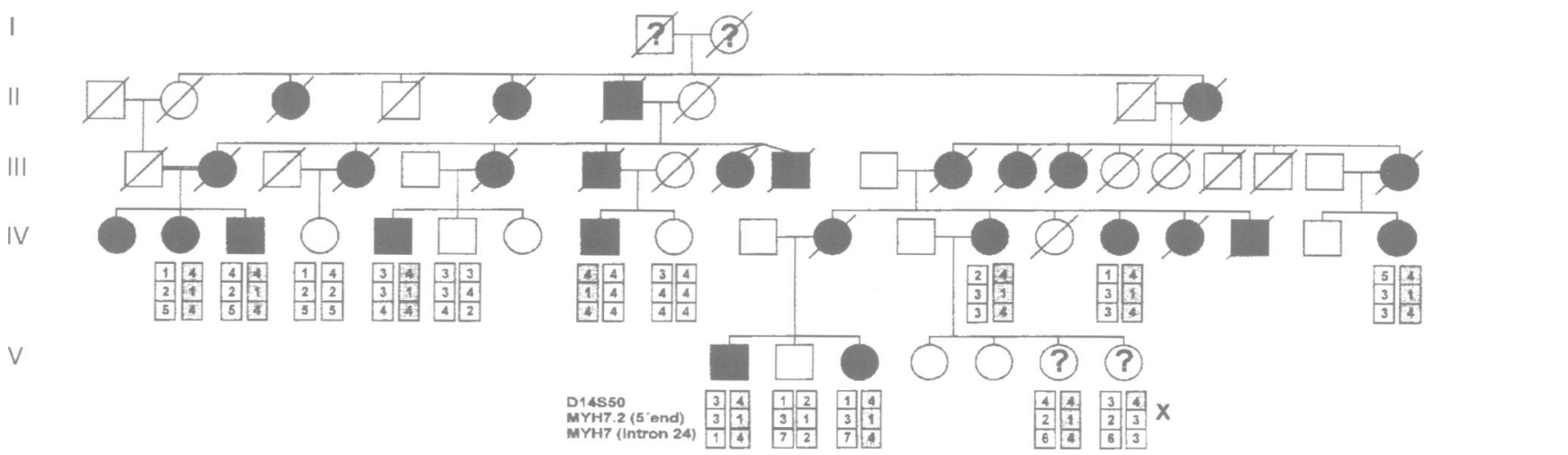
Figure 1 (A) Pedigree of the Friesian family and (B) pedigree of the Bavarian family. Haplotypes given for the three closest STS markers; the risk
haplotype is marked in grey. 
Table 1 Lod score table of OPMD v TCRD, D14S50, MYH7.2, MYH7, and D14S54

\begin{tabular}{llllllll}
\hline \multicolumn{7}{c}{ Lod score at $\theta$ of } \\
\cline { 2 - 8 } & 0 & 0.01 & 0.05 & 0.10 & 0.20 & 0.30 & 0.40 \\
\hline TCRD & & & & & & & \\
Family 1 & $-\infty$ & -8.56 & -4.33 & -2.59 & -1.08 & -0.42 & -0.13 \\
Family 2 & -8.94 & -3.16 & -1.48 & -0.79 & -0.25 & -0.09 & -0.05 \\
Total & $-\infty$ & -11.73 & -5.81 & -3.37 & -1.33 & -0.52 & -0.18 \\
D14S50 & & & & & & & \\
Family 1 & 6.44 & 6.31 & 5.80 & 5.14 & 3.78 & 2.37 & 0.98 \\
Family 2 & 2.36 & 2.31 & 2.10 & 1.84 & 1.30 & 0.77 & 0.31 \\
Total & 8.80 & 8.62 & 7.90 & 6.98 & 5.08 & 3.15 & 1.29 \\
MYH7.2 (5' end) & & & & & & & \\
Family 1 & 5.69 & 5.58 & 5.12 & 4.54 & 3.36 & 2.16 & 0.99 \\
Family 2 & 2.23 & 2.20 & 2.05 & 1.82 & 1.30 & 0.77 & 0.31 \\
Total & 7.92 & 7.78 & 7.17 & 6.36 & 4.66 & 2.93 & 1.29 \\
MYH7 (intron & $24)$ & & & & & & \\
Family 1 & 4.67 & 4.58 & 4.20 & 3.71 & 2.67 & 1.58 & 0.58 \\
Family 2 & 3.69 & 3.61 & 3.28 & 2.87 & 2.04 & 1.22 & 0.50 \\
Total & 8.36 & 8.19 & 7.48 & 6.58 & 4.71 & 2.80 & 1.09 \\
D14S54 & & & & & & & \\
Family 1 & -50.85 & -1.95 & -0.12 & 0.44 & 0.66 & 0.54 & 0.30 \\
Family 2 & 1.45 & 1.41 & 1.25 & 1.06 & 0.70 & 0.39 & 0.14 \\
Total & -49.40 & -0.54 & 1.13 & 1.50 & 1.36 & 0.93 & 0.45 \\
\hline
\end{tabular}

(MYH7) by linkage analysis of flanking and intragenic markers. ${ }^{5}$

We studied two large German pedigrees, one from northern Germany (Friesland) ${ }^{4}$ and the other from Bavaria. ${ }^{9}$ Both pedigrees can be traced back to before the Huguenot immigration from France to Germany in the 17th/ 18 th century, and there are no French ancestors. The risk haplotype (fig 1) is not shared by the members of our two families. Haplotype analysis was performed with the STR markers TRCD, D14S50, MYH7(intron 24), MYH7.2 (5' end), and D14S54 in order to confirm linkage and to exclude heterogeneity in OPMD.

For the genetic analysis, the phenotype of the family members was defined according to their clinical and neurophysiological symptoms and status. ${ }^{4}$ Intranuclear filaments were found in muscle biopsies of two patients from each family (data not shown). Whereas CK values in the Friesian family were unexpectedly normal in most patients, ${ }^{4}$ all affected members in the Bavarian family have raised values (2-6 times normal). Family members less than 45 years of age and three patients with mild muscle weakness because of a rheumatic disease or a carnitine deficiency were considered as unknown with respect to their OPMD status.

Informed consent for blood sampling was given by all family members. DNA was isolated by standard procedures from EDTA blood samples. ${ }^{10}$ STS marker typing was done

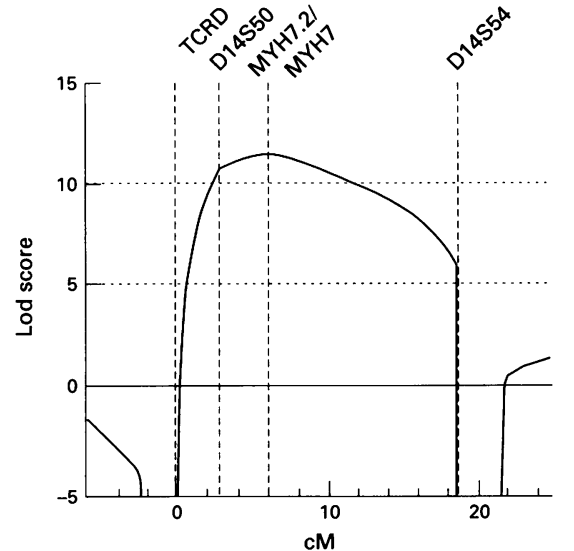

Figure 2 Graph of the multipoint linkage Figure 2 as described previously. ${ }^{5}$ The pedigrees of the two families are given in fig 1 with the risk haplotypes marked in grey. To allow simultaneous use of all the markers shown in the multipoint analysis, the pedigrees were subdivided into smaller subsets. Multipoint analysis was performed using either GENEHUNTER $^{11}$ or VITESSE, ${ }^{12}$ depending on the subset studied. Multipoint lod scores were added over all subsets to obtain fig 2. As a genetic model, autosomal dominant inheritance with $100 \%$ penetrance above the age of 45 and a gene frequency of 0.00001 were chosen.

The two point lod scores are given in table 1. Unequivocal haplotypes can be derived for the marker alleles in each of the two OPMD families (fig 1). These haplotypes cosegregate with the disease in 14 affected subjects in family 1 and with nine affected subjects in family 2 . These data generate a maximum cumulative lod score of $Z=11.3$ by multipoint linkage analysis. Our results confirm the location of the OPMD gene in close vicinity to the MYH7 locus for both families. They provide no evidence for heterogeneity in populations other than the French Canadians.

A graph of the multipoint lod scores is shown in fig 2 . The peak of the curve suggests a position for the OPMD locus which is slightly different from the MYH7 gene. Unfortunately, both probands bearing a recombination between the STS markers are too young for phenotypic classification, so that the region of interest cannot be narrowed further. Interestingly, the gene locus of another autosomal dominant myopathy maps to the same chromosomal region, namely one type of Welander distal myopathy (OMIM 160500). However, the clinical manifestations of this myopathy are quite distinctive from OPMD. Indeed, no mutation of the MYH7 gene has been reported for OPMD patients so far. Given the involvement of MYH7 in familial dilated cardiomyopathy, ${ }^{13}$ it is difficult to envisage how other mutations in the myosin heavy chain gene could explain the symptoms of OPMD.

This work was funded by the Deutsche Gesellschaft für Muskelkranke e V, Freiburg/Germany. WOLFRAM KRESS BIRGIT HALI IGER-KEL IER TIEMO GRIMM
Institute of Human Genetics, Biozentrum, University of Würzburg, Am Hubland, D-97074 Würzburg, Germany

HILDBURG PORSCHKE

Department of Neurology, University Hospital Kiel, Germany

ANDREAS ENGELHARDT

Department of Neurology, University Hospital Erlangen, Germany

HANS-HILMAR GOEBEL Department of Neuropathology, fohannes Gutenberg-University, Mainz, Germany BERTRAM MÜLLER-MYSOK Bernhard Nocht Institute for Tropical Medicine, Hamburg, Germany

1 Victor M, Hayes R, Adams RD. Oculopharyngeal muscular dystrophy. A familial disease of late life characterized by dysphagia and progressive ptosis of the eyelids. N Engl $\mathcal{f}$ Med 1962;267:1267-72.

2 Tomé FMS, Fardeau M. Nuclear inclusions in oculopharyngeal muscular dystrophy. Acta Neuropathol 1980;49:85-7.

3 Pratt MF, Meyers PK. Oculopharyngeal muscular dystrophy: recent ultrastructural evidence for mitochondrial abnormalities. Laryngoscope 1986;96:368-73.

4 Porschke H, Kress W, Reichmann H, Goebel HH, Grimm T. Oculopharyngeal muscular dystrophy (OPMD) and carnitine deficiency in dystrophy (OPMD) and carnitine deficiency in 1997; 7(suppl 1):57-62.

5 Brais B, Xie XG, Sanson M, et al. The oculopharyngeal muscular dystrophy locus maps on the region of the cardiac alpha and beta myosin heavy chain genes on chromosome 14q11.2-q13. Hum Mol Genet 1995;4:429-34.

6 Tomé FMS, Fardeaux M. Oculopharyngeal muscular dystrophy. In: Engel GA, FranziniArmstrong C, eds. Myology. 2nd ed. New York: McGraw-Hill, 1994:1233-41.

7 Klostermann W, Wessel K, Reusche E, Kessel C, Kömpf D. Okulopharyngeale Muskeldystrophie. Nervenarzt 1990;61:351-55.

8 Teh BT, Sullivan AA, Famebo F, et al. Oculopharyngeal muscular dystrophy (OPMD) - report and genetic study of an Australian kindred. Clin Genet 1997;51:52-5.

9 Engelhardt A, Böhm B, Claus D, Rott HD, Neundörfer B. Bericht über eine Grossfamilie meundorfer B. Bericht uber eine Grossfamilie mit okulopharyngealer Musk
Dtsch Ges Neurol 1989;5:888.

10 Miller SA, Dykes DD, Polesky HF. A simple salting out procedure for extracting DNA from human cells. Nucleic Acids Res 1988;16:1215.

11 Kruglyak L, Daly MJ, Reeve-Daly MP, Lander E. Parametric and nonparametric linkage analysis: a unified multipoint approach. $\mathrm{Am}$ Hum Genet 1996;58:1347-63.

12 O'Connell JR, Weeks DE. The Vitesse algorithm for rapid exact multilocus linkage analysis via genotype set-recoding and fuzzy inheritance. Nat Genet 1995;11:402-8.

13 Vikstrom KL, Leinwand LA. Contractile protein mutations and heart disease. Curr Opin Cell Biol 1996;8:97-105.

\section{Another holoprosencephaly locus at $7 \mathbf{q} 21.2$ ?}

In this journal, Benzacken et al described four new cases of holoprosencephaly in fetuses with different distal and proximal rearrangements of the long arm of chromosome 7 . Three of them showed terminal deletion of $7 q$, confirming the importance of the $7 q 36$ region in holoprosencephaly. In the fourth fetus (case 2 with semilobar holoprosencephaly and agenesis of corpus callosum and no associated malformations), an apparently balanced de novo translocation $t(7 ; 13)(q 21.2 ; q 33)$ was found. The authors suggested that this observation could be explained by the existence in $7 \mathrm{q} 21.2$ of another structural gene involved in the complex prosencephalon developmental process.

Recently, we had the opportunity to examine a 21 year old, mildly mentally retarded 